applicable, cheap, harmless, and rapidly executed even by persons with very little medical training. If, as is hoped, the test proves to be an efficient screening method I feel it would be logical to introduce it on a much wider scale. Cystic fibrosis is more common than phenylketonuria and screening for this is certainly more expensive in time and money than the method described for cystic fibrosis.-I am, etc.,

A. M. Deall

Penrith, Cumberland

\section{Treatment of Opium Addiction}

SIR,-In the Punjab in 1967 I came across a Hakim who was employing a selfdispensed liquid medicine to cure the drug habit in opium addicts. His results, which were quite successful, intrigued $m e$ and I ultimately succeeded in getting the secret recipe of the liquid. It turned out to be a decoction of green oats.

I found it listed in the National Formulary 1 and the United States Dispensatory ${ }^{2}$ as Avena sativa, but there was no mention there of therapeutic properties. No formal record has so far been traced with regard to its use in opium addicts. An alcoholic extract of the whole plant excluding the root was obtained. A clean, healthy mature plant was selected just prior to the harvest. An extract of the fresh plant was made in the ratio of $1.5: 5$ parts of $90 \%$ ethyl alcohol at room temperature over a period of 72 hours. During this time the mixture was frequently shaken. Finally, the solution was filtered. The active principle has not been identified. No other opium derivatives, barbiturates, or any form of psychotherapy was used. A 2-ml dose of the extract, suitably diluted, was given t.i.d.

Ten chronic opium addicts who had attended a clinic at the Susheela Mehra Memorial Hospital, Jullundur City, Punjab, for other medical reasons were asked if they would consider trying a drug to break the opium habit. They were not very enthusiastic of the final outcome as previous treatments had uniformly failed. However, they all gave their consent. All the patients were men, and the trial took place in 1968-9. The average age was 42 years. The length of the habit varied from 3 to 20 years (average 10.8 years), and the oral ingestion of opium per day varied from $0.5 \mathrm{~g}$ to $4.0 \mathrm{~g}$. Average daily intake was $1.65 \mathrm{~g}$ at the start of treatment. During its course most patients were able to reduce the opium intake gradually. "Restless legs," mainly at night, were observed in six of the 10 patients; there was also difficulty in falling asleep during the reduction of opium. All these patients had in the past tried various treatments to come off opium and they were extremely dubious of getting any result. The drug was thus taken without any bias or expectations. No manner of psychotherapy, opiates, or any other substitution therapy was employed. Under the effect of the extract the patients could reduce their daily opium intake themselves, and this reduction was made on the patients' own initiative. They were never asked to reduce their opium intake. They had free access to opium and no control on its availability to them was either possible or applied. Thus, there was no supervised or graded with- drawal which is known to be an effective management of opium addiction.

No serious withdrawal symptoms were noticed nor were there any side effects attributable to the drug. The observation that nine out of ten patients continued with their work during treatment excluded any marked changes in behaviour and general well being. The Avena sativa treatment varied from 27-45 days (average 34 days), after which it was not repeated.

At the end of the trial six had given up opium; two had reduced it, and two showed no change. At the last follow-up, which varied from 3-19 months (average 7.7 months) after the cessation of treatment, the daily average intake was $0.56 \mathrm{~g}$. Six patients were still off opium or any of its derivatives or barbiturates; two had reduced their opium intake; and two showed no change.

The drug has never been applied in the management of the opium habit and as the problem of addiction remains so distressing and formidable, a detailed study of the role of this drug seems justified.

During this treatment some patients also lost their craving for cigarettes. A study in cigarette smokers is under way.-I am, etc.,

C. L. Anand

1 American Pharmaceutical Association. National Formulary of the United States of America, 7th Ed., p. 60. Washington, American Pharma-

21 st Ed., Part I, p. 208. Philadelphia America, cott, 1921.

Diazepam and Neuromuscular Blocking Drugs

SIR,-According to Drs. S. A. Feldman and B. E. Crawley (9 May 1970, p. 336; 14 March 1970, p. 691) diazepam potentiates gallamine in man, and gives rise to persistent postoperative muscle weakness and respiratory depression. However, other workers $^{12}$ have found no significant interaction between diazepam and neuromuscular blocking drugs.

We have carried out experiments on cats to study the possibility of any interaction between diazepam and gallamine at the neuromuscular junction. Eight cats were anaesthetized, as in the clinical situation described by Drs. Feldman and Crawley, with thiopentone induction, $\mathrm{N}_{2} \mathrm{O} / \mathrm{O}_{2}(30 \%)$, and halothane $(0.5-2 \%)$ maintenance. Maximal twitches of the flexor hallucis longus and
Glasgow N.W. Dispensatory of the 1942. rectangular severed sciatic nerve contractions were recorded duration. The (model 79) twin-channel pen recorder. A constant dose of either gallamine $(0.75-1 \mathrm{mg} /$ $\mathrm{kg})$ or tubocurarine $(0 \cdot 1-0.4 \mathrm{mg} / \mathrm{kg})$ was injected intravenously at intervals of $30 \mathrm{~min}$ to $2 \mathrm{hr}$. The dose and the interval between doses were constant in any one experiment. With the longer dose intervals, cumulative effects of the blocking drugs were minimized. Diazepam itself, in doses of $0 \cdot 2-0.4 \mathrm{mg} / \mathrm{kg}$ intravenously given in the commercially available solution for injection, was without effect on the contractions, as also reported by others. ${ }^{34}$ Nor did these doses of diazepam, given either 5 minutes prior to the neuromuscular blocking drug or at the maximal degree of block, alter in any way the depth or time course of the blocks produced by tubocurarine or gallamine in either muscle (Fig.).

Larger doses of the diazepam injection, containing $1 \mathrm{mg} / \mathrm{kg}$ of diazepam, slightly enhanced the rate of recovery from neuromuscular block produced by gallamine or tubocurarine, but there was never any sign of enhancement of the block. Control experiments with the diazepam solvent (propylene glycol $41.4 \%$, ethanol $8 \cdot 1 \%$, benzoic acid $0.12 \%$, sodium benzoate $4.88 \%$, benzyl alcohol $1.57 \%$ in water) showed that the whole of this weak antagonistic action could be attributed to the solvent.

We conclude that, in the anaesthetized cat, diazepam does not interact with gallamine or tubocurarine at the neuromuscular junction, and we were therefore unable to find any support for the observation of Drs. Feldman and Crawley in man. Our findings are in agreement with those recently published by Dretchen et al. ${ }^{5}-\mathrm{We}$ are, etc.

Pharmacology Department,

SANDRA N. WEBB Strathclyde University

Department of Anaesthetics,
University of Glasgow

Elizabeth G. Bradshaw

Stovner, J., and Endresen, R., Lancet, 1965, 2,

1298.
Hunter, A. R., British fournal of Anaesthesia, 1967, 39, 633.

Crankshaw, D. P., and Raper, C., British fournal of Pharmacology, 1968, 34, 579.

P. F. Knight, and C. Diazepam in Anaesthesia, ed. Wright 1968 .

5 Dretchen, K., Ghoneim, M. M., and Long, J. P.,
Anesthesiology, 1971, 34, 463.,

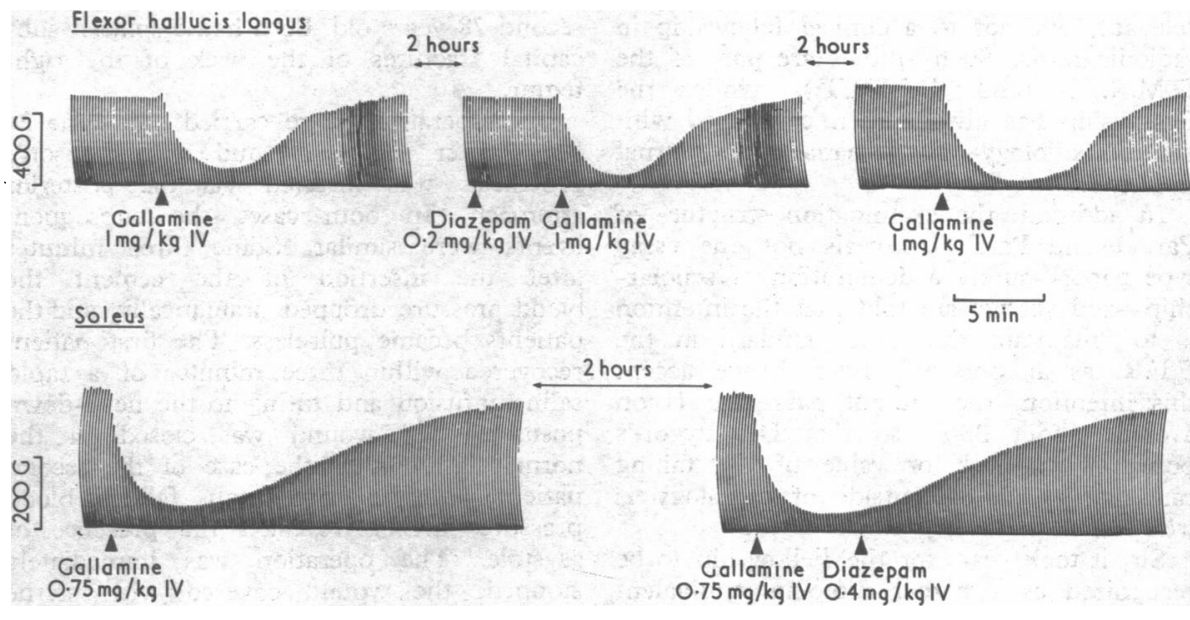

Frg.- Maximal twitches of cat flexor hallucis longus muscle and cat soleus muscle elicited indirectly once 